\title{
The advantage of experience: Analyzing the effects of player experience on the performances of March Madness teams
}

\author{
N. David Pifer ${ }^{\mathrm{a}, *}$, Timothy D. DeSchriver ${ }^{\mathrm{b}}$, Thomas A. Baker III' ${ }^{\mathrm{c}}$ and James J. Zhang ${ }^{\mathrm{c}}$ \\ a Sport Management, Texas Tech University - Lubbock, TX, USA \\ ${ }^{\mathrm{b}}$ Sport Management, University of Delaware - Newark, DE, USA \\ ${ }^{\mathrm{c}}$ Department of Kinesiology (Sport Management), University of Georgia - Athens, GA, USA
}

\begin{abstract}
Every March a sample of the top Division I men's basketball programs in the National Collegiate Athletic Association (NCAA) gather to compete in March Madness, a grueling single elimination tournament that captures the attention of millions of viewers and shines a prominent spotlight on the 68 teams that are competing for college basketball's national championship. Interspersed amongst the numerous financial incentives that exist for each university, and the millions of dollars that are wagered on brackets and bets, are the suggestions of media members, coaches, and players as to which factors are important to teams in their quest for success. One common suggestion argues that player experience provides a benefit to teams as they attempt to handle the pressure and maintain their composure amidst one of the most hectic postseasons in all of sport. However, there have been few studies conducted to analyze the effects that the two primary categories of player experience (i.e., prior postseason experience and class rank) have on the performances of March Madness teams. Therefore, this study sought to test the validity of the assumption by using a series of empirical models to analyze player performance and experience data from the 693 games that took place during the 2007 to 2017 March Madness tournaments. The findings suggest that simply having a higher class rank than an opponent offers no discernible advantage at any stage of the competition, but that possessing more prior March Madness experience may significantly improve a team's margin of victory in the later rounds.
\end{abstract}

Keywords: NCAA, basketball, performance analytics, prior experience, class rank

\section{Introduction}

Each March, the top men's basketball programs in the National Collegiate Athletic Association's (NCAA) highest division (Division I) compete in the NCAA Men's Basketball Championship, a sixstage, single elimination tournament known more commonly as March Madness. This annual event marks the culmination of the college basketball season and crowns the last team standing as the national champion. With each do-or-die matchup featuring

\footnotetext{
*Corresponding author: N. David Pifer, Texas Tech University, Kinesiology \& Sport Management, Box 43011, Room 135, Lubbock, TX 79409, USA. Tel.: +1 806834 2346; E-mail: david. pifer@ttu.edu.
}

two of the top teams in the nation competing against one another in a game that is being broadcast to millions of viewers (Pallotta, 2015), the action is intense and the margins for error are slim. Win, and a team moves one step closer to the title; lose, and it must exit the tournament with an eye toward the future. "If you lose one game, it's over," notes former NCAA standout Kenny Anderson. "To win it all you have to win six games, and it's an especially large amount of pressure to continue to win" (Anderson, 2016, para. 2).

Indeed, March Madness games present teams with a variety of internal and external stressors that are far different from what they experience throughout the course of the regular season. On this stage, 
players must consistently perform at a high level while remaining cognizant of the fact that a loss signals the end of a season and potentially a career. They must also bear the emotional burdens of hundreds of thousands of stakeholders, some of whom may be supplying the program with financial benefits (e.g., increased donor contributions, improved ticket sales, and heightened media exposure) that are contingent on a successful showing in the tournament (Goff, 2000; Humphreys and Mondello, 2007). In addition, the NCAA incentivizes teams to perform well in March Madness games by placing a share of its media rights revenues in a fund that can award conferences and teams with as much as $\$ 1.7$ million for every round of the tournament they advance to (Smith, 2017). All of these burdens and expectations are then further compounded by a national television spotlight that places these young athletes in front of media pundits who stand ready to dissect their performances on national television and professional scouts who will be determining whether or not they have what it takes to play at the next level. For the players who are not accustomed to it, the distractions and stresses supplied by these entities can add additional pressure to an already grueling tournament.

Given these added complexities, it should come as little surprise that March Madness regularly serves as a setting for one of the most oft-cited clichés in sport. Indeed, the assumption that player experience is an important determinant in the outcome of postseason sporting contests has become an integral part of the vernacular preached by March Madness coaches, players, and media members each season (Lopresti, 2016; Wolstat, 2014). The term experience, as applied in this context, is typically categorized in one of two ways. First, it is often used in reference to the specific amount of postseason experience (i.e., March Madness experience) accrued by a team's players in the past. In this sense, the teams with players who have "been there and done that" should be accustomed to the tournament's unique forms of pressure and immune to the "stage fright" and "jitters" that are rumored to plague less-experienced sides. Second, experience is sometimes used in a more general sense to describe the collective age or number of seasons played by the players on a team. In this regard, a team containing more mature players (i.e., more upperclassmen) will have developed a skillset and model of consistency that should carry over to the court. While these two categorizations of experience may ultimately have varying impacts on performance, their use in the recycled rhetoric of March Madness affiliates remains the same: when faced with the prospects of elimination, the more knowledgeable, veteran players are expected to rise to the occasion while the younger, more inexperienced players are expected to fold under pressure (Tarlow, 2012). As noted by former NCAA champion Grant Hill, "The obvious advantage is experience; just having guys who have been in the game and are more mature. They've had success and maybe failures in the postseason. They just kind of understand. You can't teach that" (Lopresti, 2016, para. 17).

The frequent positioning of player experience as a key determinant in the outcome of March Madness games and other postseason sporting events would lead one to believe that this proposition has become a foundational pillar in the growing body of sports analytics literature. If pundits, coaches, and former participants are consistently propping up the experience narrative, then it stands to reason that this assumption is bolstered by a bevy of empirical evidence. However, a review of the extant literature on the subject reveals a surprising lack of studies that have sought to examine whether or not player experience affects the performances of teams competing in the postseason. In fact, a literature review on this topic discovered a small number of peer reviewed studies - one examining the NBA postseason (Tarlow, 2012), and the other looking at the NFL Playoffs (Pitts, 2016) - that have explicitly tested this assumption, and none were conducted within the contexts of March Madness or college sports in general.

Given that bracket predictions form a part of the essence of March Madness (Doty, 2017; Moyer, 2016), and that the tournament involves college athletes who may be encountering national spotlights and postseason pressures for the first time in their relatively young careers, this omission is perplexing. A review of the literature that does exist for the determinants of March Madness success instead reveals a plethora of models and metrics that have been developed for the sole purpose of forecasting game outcomes by using more traditional and tangible statistics. This only serves to further highlight the tendency for the research in this area to overlook variables such as experience that may help quantify some of a team's more intangible qualities.

Therefore, in light of the evidence suggesting that the experience assumption has gone untested in college sports and March Madness, the purpose of this study was to assess the extent to which prior 
postseason experience and class rank affected the performances of NCAA Division I men's basketball teams. Using binary probit and ordinary least squares (OLS) regression models to test the commonly-held assumption that experience affects the outcomes of March Madness games, this analysis attempted to lend statistical power to an assumption in need of further support. Ultimately, this knowledge can benefit a number of parties, including the basketball programs, media pundits, and sports gamblers who must predict and prepare for March Madness games on a regular basis.

With this purpose in mind, the remainder of the study proceeds as follows: first, the background section gives a primer on the format, financial structure, and relevance of March Madness. Second, the literature review summarizes and discusses some of the most relevant studies, their results, and the theories that ground them. Third, the data, variables, and regression models are described in the method section. Fourth, the results of the empirical analyses are presented. Fifth, the results are discussed and recommendations for future research are made. Last, a conclusion section briefly summarizes the study.

\section{Background}

March Madness is the name given to the annual, season-ending tournament that decides which NCAA Division I men's basketball team will be crowned as the national champion. Following conference tournaments and a series of play-in games known as the First Four, the event ceremoniously tips-off with 64 teams competing in the opening round of a six-stage, single elimination tournament. From the onset, teams are grouped within one of four regions and assigned a seed that ranges from 1 (strongest) to 16 (weakest). These seeds are determined by the NCAA Selection Committee and are intended to coincide with the strength of a team relative to the rest of the teams in its region (Khatibi, King and Jacobson, 2015). After the opening round in which seed numbers $n=(1$, $2,3, \ldots, 8)$ play against seed numbers $17-n$, the regional action progresses through the bracket such that the winning team from each region advances to the Final Four. At this semifinal stage, the region champions face off against one of the other region champions for the right to compete in the National Championship.

The rewards for progressing through each stage of the tournament are rather lucrative due to the massive multimedia rights deal that was negotiated between the NCAA, Turner Broadcasting, and CBS Sports in 2011. The deal, which was extended in 2016, entitles the NCAA to an annual sum of $\$ 1.1$ billion from the 2017 to 2032 postseasons (Osburn, Smeltz and Sabatelle, 2016). Traditionally, the NCAA takes anywhere from 25-30\% of its March Madness media revenues and places the sum in an incentivized pool known as the basketball fund (Ingold and Pearce, 2015). The money in this fund is then divided into equal units that are allotted to the team slots in every March Madness game from the First Four to the Final Four. As such, teams earn a single unit for every stage of the tournament they appear in prior to the National Championship. These units are paid out in six-year increments to a team's conference rather than the team itself. ${ }^{1}$

From a financial perspective, March Madness is also relevant to the millions of active observers who participate indirectly by attempting to predict match outcomes. Indeed, figures from the American Gaming Association (AGA) estimated that nearly $\$ 10.4$ billion in wagers were placed on the 2017 edition of the tournament through office pools, Nevada sports books, offshore sites, and illegal bookies (Doty, 2017). Many of these bets were fueled by bracketology, the art of attempting to successfully predict March Madness winners (Jacobson, Nikolaev, King and Lee, 2011). This popular practice has grown to encompass some 40 million Americans who complete a combined 70 million brackets while wagering an average of \$29 per bracket (Doty, 2017). In many ways, bracketology has become as much a staple of the tournament as the games themselves. Overall involvement in this activity is so pronounced that it is estimated to cost businesses $\$ 4$ billion in lost productivity during the first week of March as employees spend an average of three hours making predictions and watching games in the office (Pedderson and Madden, 2016). Further estimates show that bracketology, alone, is capable of boosting tournament viewership by $21 \%$ (Moyer, 2016). It is no wonder, then, that media outlets devote such a considerable amount of time to the forecasting of March Madness outcomes. With a substantial percentage of their viewers having an interest and investment in bracket predictions, it serves them well to disseminate information that will assist bracketologists in their mission to accurately predict the results of March Madness games. However, danger lies in accepting unproven assumptions as fact and in giving too much credit to something which seems obvious (Moskowitz and 
Wertheim, 2011). To this end, those relaying the generalizations and clichés should do more to ensure that the rationales for these assumptions are wellgrounded; after all, nearly 40 million Americans have something at stake in their predictions (Doty, 2017).

\section{Literature review}

Throughout the years, academic investigators and basketball statisticians have attempted to predict the outcomes of March Madness games using a wide array of explanatory variables and empirical methods. Some of the earliest analyses used the seed assigned to each team as a rather intuitive means of predicting the likelihood that a team would win and the margin by which it would do so (Boulier and Stekler, 1999; Caudill, 2003; Schwertman, Schenk and Holbrook, 1996; Smith and Schwertman, 1999). The collective findings of these initial studies indicated that an obvious advantage exists for a team that possesses a higher seed than its regional opponents; however, subsequent analyses showed that the relationship between seed and performance breaks down as the tournament progresses (Baumann, Matheson and Howe, 2010; Jacobson and King, 2009).

To this end, additional studies have investigated a variety of predictors other than seed. These variables have ranged from simple measures such as regular season winning percentages, margins of victory in regular season games, records against tournament teams, and Vegas point spreads, to more complex ratings (e.g., NCAA RPI measures; KenPom, Sagarin, and Massey ratings) that are specific to an organization or website (Carlin, 1996; Harville, 2003; Hoegh et al., 2015; Kvam and Sokol, 2006). Many studies employ methods that simultaneously incorporate several of these variables in their models. Others compare the predictability of these measures and models in order to determine which ones are most accurate. The logit regression/Markov-chain model developed by Kvam and Sokol (2006), for example, incorporated variables such as margin of victory, game location, and strength of schedule into its metrics and was found to be more predictive than Vegas betting odds and other common ranking systems.

Absent from many of these models, though, are variables incorporating the intangible qualities of teams and their opponents. In this regard, the more discrete benefits afforded by an attribute like experience have gone largely ignored in the existing body of sports analytics literature. This gap is perplexing considering that a number of studies in areas outside of sport have highlighted the various advantages that experience can provide to people performing tasks in specialized scenarios. In the criminal justice realm, for example, studies have shown that experience can help police officers appraise and respond to stressful situations more appropriately (Anshel, Robertson and Caputi, 1997; Larsson, Kempe and Starrin, 1988). Likewise, natural disaster victims and musical performers who are accustomed to the stresses of a flood or audition are less likely to experience feelings of distress and anxiety during future occurrences of an event (Norris and Murrell, 1988; Van Kemenade, Van Son and Van Heesch, 1995). There even exists a theory, the inoculation hypothesis, designed to explain how exposure to a specific form of stress increases one's resistance to subsequent levels of that stress (Eysenck, 1983).

The fields of economics and business management also contain a variety of studies that have categorized experience as an asset. A meta-analysis performed by Quińones, Ford, and Teachout (1995) in this area condensed the findings of over 40 studies and revealed that experience and job performance were positively related across a variety of industries, job positions, and performance measures. Seeing as experience can offer a number of general and specific benefits to individuals and organizations across a variety of disciplines, it remains surprising that so few studies have analyzed this concept as it relates to the postseason performances of collegiate sports teams. After all, studies have shown that athletes are susceptible to choking under pressure (Baumeister, 1984; Baumeister and Showers, 1986; Beilock and Carr, 2001; Goldman and Rao, 2012; Wallace, Baumeister and Vohs, 2005), and a theory like the inoculation hypothesis shows why prior experience could be valuable to teams competing in postseason scenarios where the pressure is high. If experience is advantageous to people and organizations in so many other high-pressure settings, then it stands to reason that this asset will carry over to the performances of players and teams competing in March Madness and other postseason sporting events.

However, in the context of sport, at any level, there is a rather limited selection of studies that have focused primarily on the impact that player experience has on teams competing in the postseason. One study attempted to forecast the number of playoff games an NBA team would win using multiple least squares regression and experience variables that represented the number of years a player had 
played in the NBA, the number of prior postseason games a player had played, and the number of years of shared experience that existed between any two starters on a team (Tarlow, 2012). Including these measures alongside a host of control variables, only the shared experience measure, as a proxy of team chemistry, was found to be a significant determinant of postseason wins. ${ }^{2}$ Another study that examined this phenomenon used binary probit regression models to analyze NFL playoff games and how the comparative levels of prior postseason experience held by each team and its key players affected the likelihood of a game being won (Pitts, 2016). The relevant prior experience variables in this analysis were coded as the advantage or disadvantage that a team held compared to its opponent in the areas of quarterback postseason experience (i.e., the number of previous playoff games started by a quarterback minus the number of previous playoff games started by his opponent) and team postseason experience (i.e., the number of playoff games a team had competed in minus the number of playoff games its opponent had competed in). Ultimately, neither form of experience was found to afford NFL teams with any significant advantage. Simply possessing players with more postseason experience than an opponent did not improve a team's chances of winning. ${ }^{3}$

Taken together, the primary findings of these aforementioned studies seem to imply that the experience narrative being preached by members of the media each postseason is overstated and unfounded. Pitts (2016) notes that the results "are not consistent with the purported importance of previous playoff experience by many fans and media" (p. 105). Similarly, Tarlow (2012) makes reference to the media and states that "the most common criticism is of the inexperience of younger teams and this study does not support this conclusion, regardless of whether their NBA experience or playoff experience is the topic of discussion" (p. 8). If taken verbatim, these conclusions would suggest that researchers do not need to map out the intangible qualities of a team because raw measures of performance, alone, are more capable of predicting success. However, a possible explanation for the insignificance of these findings is that most professional athletes are already accustomed to dealing with the pressures of a big game. Even those players who have little to no postseason experience at the professional level have already participated in college and regular season games where the stakes were high and the scrutiny was intense. Thus, it is not unreasonable to assume that professional ath- letes have developed effective coping strategies to ensure that they are not unprepared or overwhelmed in future postseason games. A further explanation for why these findings may not hold weight is that both analyses used very general measures of experience (games played) and performance (wins) that may not fully capture the intangible benefits that experience can offer. As noted by Quińones et al. (1995), the more specific measures of experience and performance tend to display the most powerful effects. Therefore, this review of literature and the abundance of theories that naturally support the experience assumption make it clear that further analyses are needed to test this phenomenon at the collegiate level of play.

\section{Methodology}

\subsection{Data}

The majority of the data in this study were derived from www.sports-reference.com/cbb and www.teamrankings.com, two reliable online archives for historical college basketball statistics. These websites contain the postseason box scores, team roster pages, and team statistics that were used to compile a dataset consisting of all 693 March Madness games (excluding play-in games) that were played from 2007 to 2017. In addition, www.kenpom.com was used to obtain data pertaining to the effective heights of each team. All data were manually pulled from their respective sources, recorded, and then analyzed using a combination of procedures in the $\mathrm{R}$ 3.3.1 and IBM SPSS Statistics 20 software packages.

The timeframe used in this sample was chosen because of its recency and because all seasons were played with the "one-and-done" rule in effect (i.e., as of the 2006 NBA draft, all high school players from the United States were required to attend one year of college before entering the NBA). Each observation in the eleven-season sample corresponds to a single March Madness game. This format was chosen per the recommendations set forth by Robst, VanGilder, Berri, and Vance (2011), and Pitts (2016), which highlighted the issues of independence that can arise when the outcome of a single game is treated as two separate events. ${ }^{4}$ In order to avoid this dilemma, one participating team was randomly (alphabetically) assigned to be the team, $i$, and the other to be the opponent, $j$, while the explanatory statistics were recorded as the difference between the two $(i-j)$. The explana- 
Table 1

Summary of the Explanatory and Outcome Variables

\begin{tabular}{|c|c|}
\hline Variable & Description \\
\hline & EXPLANATORY VARIABLES \\
\hline$W_{I N} \%^{\mathrm{a}}$ & The current win-loss percentage of a team minus the WIN\% of its opponent \\
\hline $\operatorname{SOS}^{\mathrm{a}}$ & $\begin{array}{l}\text { The current strength of schedule rating for a team (denominated in points above or below average, where zero is } \\
\text { average) minus the SOS rating of its opponent }\end{array}$ \\
\hline$O R T G^{\mathrm{a}}$ & $\begin{array}{l}\text { The current offensive efficiency rating (points scored per } 100 \text { possessions) for a team minus the ORTG of its } \\
\text { opponent }\end{array}$ \\
\hline$D R T G^{\mathrm{a}}$ & $\begin{array}{l}\text { The current defensive efficiency rating (points allowed per } 100 \text { possessions) for a team minus the DRTG of its } \\
\text { opponent }\end{array}$ \\
\hline$C O A C H^{b}$ & The number of prior March Madness games a team's head coach has coached in minus the COACH of its opponent \\
\hline$E H T^{\mathrm{c}}$ & $\begin{array}{l}\text { The effective height of a team minus the EHT of its opponent; EHT is representative of the number of inches in } \\
\text { height a team's power forwards and centers are above average }\end{array}$ \\
\hline$M M E X P 5^{\mathrm{b}}$ & $\begin{array}{l}\text { The average amount of prior March Madness minutes played by a team's top five players in minutes played during } \\
\text { the observed game minus the MMEXP5 of its opponent }\end{array}$ \\
\hline$M M E X P S U B^{\mathrm{b}}$ & $\begin{array}{l}\text { The average amount of prior March Madness minutes played by a team's remaining players who played at least } 4 \\
\text { minutes in the observed game minus the MMEXPSUB of its opponent }\end{array}$ \\
\hline CLASS5 $5^{\mathrm{b}}$ & $\begin{array}{l}\text { The average class rank (where } \mathrm{FR}=1, \mathrm{SO}=2, \mathrm{JR}=3, \mathrm{SR}=4 \text { ) of a team's top five players in minutes played during } \\
\text { the observed game minus the CLASS5 of its opponent }\end{array}$ \\
\hline CLASSSUB $^{\mathrm{b}}$ & $\begin{array}{l}\text { The average class rank of a team's remaining players minus the CLASSSUB of its opponent (players had to play for } \\
4 \text { minutes in the game to be counted) }\end{array}$ \\
\hline LATEROUND ${ }^{\mathrm{b}}$ & $\begin{array}{l}\text { Equals } 1 \text { if an observed game was taking place in the Sweet } 16 \text { or beyond; this variable was interacted with the other } \\
\text { explanatory variables in order to examine whether there were differential effects as the tournament progressed }\end{array}$ \\
\hline & OUTCOME VARIABLES \\
\hline$W I N^{\mathrm{b}}$ & Equals 1 if the team won its game and 0 if it lost \\
\hline$M A R G I N^{\mathrm{b}}$ & Points scored by a team minus the points scored by its opponent \\
\hline
\end{tabular}

${ }^{\mathrm{a}}$ www.teamrankings.com; ${ }^{b}$ www.sports-reference.com; www.kenpom.com.

tory variables included in this study encompassed two categories of experience and a host of variables designed to control for the basic strengths of a team. There are two outcome variables examined in this study. The first, accordingly labeled as WIN, is a binary representation of whether a team won or lost its March Madness game. This variable received a value of $l$ if team $i$ won the game and a value of 0 if team $j$ won (i.e., team $i$ lost). In addition, a margin of victory/defeat outcome variable (MARGIN) was included in an effort to more precisely examine the factors that are important in determining the amount by which a team wins or loses. Table 1 summarizes all of the explanatory and outcome variables that were used in this study. The following section describes the rationale for why the chosen explanatory measures were included in the empirical analyses.

\subsection{Explanatory variables}

In an effort to more clearly depict the effects that experience may have on the outcome variables, two different measures of experience were employed in this study. The first fell within the prior March
Madness experience category and was representative of the number of career minutes accumulated by a team's players in previous March Madness games. The decision to use minutes played as the measure of postseason experience instead of the game appearances metric used in prior studies (Pitts, 2016; Tarlow, 2012) was intended to lend these variables an element of specificity that is known to yield more powerful results (Quińones et al., 1995). Rather than weighting the prior experience of a player who appeared for one minute at the end of a blowout as being equal to the prior experience of a player who played for the majority of a game, the use of minutes played allowed for a more comprehensive assessment of the impact that prior March Madness experience had on performance.

To this end, the MMEXP5 and MMEXPSUB variables were designed to capture the average amount of prior March Madness experience held by the two main tiers of players on a team. MMEXP5 took the average amount of prior March Madness minutes played by a team's top five players in minutes played from the observed game and subtracted the opponent's MMEXP5 value to leave the relative advantage 
or disadvantage that was being held by the team in terms of previous March Madness experience. The additional tier of the variable (MMEXPSUB) was included in order to account for the diminishing returns that are received from substitute players who play less minutes in a given game. This helped control for the discrepancies that may arise if the prior experience totals of fringe players are weighted as heavily as the players who appear most frequently. In order to be counted in the MMEXPSUB category, players had to have appeared for at least 4 minutes ( $10 \%$ of total team minutes) in the observed game. This threshold prevented players who appeared in "garbage time" at the end of a blowout win or loss from being weighted the same as the players who made more meaningful contributions. Just like the MMEXP5 variable, MMEXPSUB represented the marginal difference between a team and its opponent.

The CLASS5 and CLASSSUB variables were designed to operate in a fashion similar to the March Madness experience variables, albeit with a more general representation of experience. In many settings, experience is viewed as being synonymous with a person's age or the number of years they have been on the job. Within the realm of college sports, experience generally coincides with the class rank of an individual student athlete. First year players are classified as freshmen, second year players as sophomores, third year players as juniors, and fourth year players as seniors. By averaging the numerical values that coincide with the respective class of each player $(\mathrm{FR}=1, \mathrm{SO}=2, \mathrm{JR}=3, \mathrm{SR}=4)$, class rank values can be formed for a team and its opponent. As such, the CLASS5 variable represented the difference between the average class ranks of the top five players in minutes played for the two teams in the observed game. It was viewed as being important for explaining the numerous advantages that are said to arise from having key players who are more mature and more accustomed to the nuances of the college game (Lopresti, 2016; Wolstat, 2014). Subsequently, the CLASSSUB variable represented the relative difference between the average class rankings of a team's remaining players and the coinciding CLASS$S U B$ value of its opponent. This variable might show whether or not upperclassmen who do not play as much are still capable of contributing and inspiring as role players. Just like MMEXPSUB, the CLASSSUB variable was set to include only those players who appeared for 4 minutes or more in an observed game.

The remaining explanatory variables were primarily included to control for factors outside of experience that may be related to the relative quality of a team. The win-loss percentage (WIN\%) of a team compared to its opponent was used as a broad indicator of relative performance quality. The strength of schedule (SOS) variable accounted for the relative quality of the opponents that each team faced in prior games through the use of a rating that was denominated in points above or below average, where zero was average (e.g., a team with an SOS value of 10 played against opponents who were, on average, 10 points better than the average team, controlling for home and away factors). ${ }^{5}$ Teams with high SOS ratings are typically those that play in "power" conferences against traditional basketball powerhouses. The offensive (ORTG) and defensive ratings $(D R T G)$ of a team were also included in order to offer more specific measures of team quality. Offensive and defensive ratings standardize the more common points-per-game and points-allowedper-game metrics by showing the number of points scored or allowed per 100 possessions. Because these ratings are more immune to the speed at which the game is being played, they are better measures of offensive and defensive efficiency (Kubatko, Oliver, Pelton and Rosenbaum, 2007). Lastly, variables signifying the differences between the levels of coaching experience $(\mathrm{COACH})$ and the effective heights $(E H T)$ of the teams being observed were also included. The $\mathrm{COACH}$ variable was included in order to control for any effects that prior March Madness coaching experience might have on a team's chances of winning a current March Madness game. Effective height (EHT), a metric espoused by Pomeroy (2008), averages the physical heights of a team's power forward and center positions. In variable form, it showed the relative height difference, in inches, between the two teams' big-men and was used to control for the advantages that may arise from being a taller team. ${ }^{6}$

It further needs to be mentioned that each of the explanatory variables were interacted with a binary categorical variable indicating whether the observed game was taking place in the Sweet 16 or beyond (LATEROUND). Sweet 16, Elite 8, Final Four, and National Championship games received a value of 1 while Round of 64 and Round of 32 games received a value of 0 . These interactions were examined because not all March Madness games are equal; that is, there will be a greater disparity in quality between teams in the early stages of the tournament than there will be later on (Bauman et al., 2010; Jacobson and King, 2009). Hypothetically, the pressure will also be building as teams get closer to the title 
game. Therefore, looking at these interaction terms allowed the researchers to assess whether or not the explanatory variables, and in particular the experience variables, had a statistically significant impact on game outcomes in the tournament's later rounds.

\subsection{Empirical specifications}

Two regression models were developed in an attempt to assess the impact that experience has on WIN and MARGIN. The first of these took the form of a probit regression model in an effort to account for the binary nature of the WIN variable and to display the marginal effect that each of the explanatory variables had on the probability of a team winning its March Madness game. As such, the following binary probit model was estimated:

$$
\begin{aligned}
\operatorname{Pr} & \left(\text { WIN }_{i j}=1\right)=\beta_{0}+\beta_{1} W_{I N} \%_{i j}+\beta_{2} \text { SOS }_{i j} \\
& +\beta_{3} O R T G_{i j}+\beta_{4} D R T G_{i j}+\beta_{5} M M E X P_{i j} \\
& +\beta_{6} C L A S S_{i j}+\beta_{7} C O A C H_{i j}+\beta_{8} E H T_{i j} \\
& +\beta_{9} L A T E R O U N D_{i j}+\varepsilon_{i j}
\end{aligned}
$$

where $W_{I N}$ equals 1 if team $i$ wins the March Madness game and $O$ if it loses to team $j, W I N \%_{i j}$ is a variable measuring the prior win-loss record of team $i$ relative to team $j, S O S_{i j}$ is the strength of schedule rating measuring the prior strength of the opponents faced by team $i$ relative to team $j, O R T G_{i j}$ is the offensive efficiency of team $i$ relative to team $j, D R T G_{i j}$ is the defensive efficiency of team $i$ relative to team $j, M M E X P_{i j}$ is the vector of variables (MMEXP5 and MMEXPSUB) describing the prior March Madness experience of team $i$ relative to team $j, C L A S S_{i j}$ is the vector of variables (CLASS5 and $C L A S S S U B)^{7}$ describing the class rank experience of team $i$ relative to team $j, C O A C H_{i j}$ is the number of prior March Madness games coached by the coach of team $i$ relative to the coach of team $j, E H T_{i j}$ is the average height difference, in inches, between the power forward and center positions on team $i$ compared to team $j$, LATEROUND $_{i j}$ is the vector of variables representing the interactions between each of the explanatory variables and a categorical variable indicating whether the game was taking place in the Sweet 16, Elite 8, Final Four, or National Championship (1), or the Round of 64 or Round of $32(0)$, the $\beta$ 's are parameters to be estimated, and $\varepsilon_{i j}$ is a random error term. In total, there were 693 observations with which to estimate Equation 1.
For MARGIN, ordinary least squares (OLS) regression was identified as the appropriate method due to the relatively continuous nature of the point differentials from the observed March Madness games. The associated OLS model was estimated as:

$$
\begin{aligned}
& \text { MARGIN } \text { I }_{i j}=\beta_{0}+\beta_{1} \text { WIN }_{i j}+\beta_{2} \text { SOS }_{i j} \\
& \quad+\beta_{3} \text { ORTG }_{i j}+\beta_{4} D R T G_{i j}+\beta_{5} M M E X P_{i j} \\
& \quad+\beta_{6} C L A S S_{i j}+\beta_{7} \text { COACH } H_{i j}+\beta_{8} E H T \\
& +\beta_{9} L A T E R O U N D+\varepsilon_{i j}
\end{aligned}
$$

where MARGIN represents the amount of points by which team $i$ won or lost its game against team $j$, and all other variables and parameters are as previously defined in the first equation. In total, there were 693 observations with which to estimate the second model. Examination of the Q-Q plots and scatter plots of the residuals confirmed that the OLS assumptions of normality, linearity, and variance were met.

\section{Results}

\subsection{Descriptive statistics}

Before examining the results of the model estimations, a look at the descriptive statistics in Table 2 helps to shed some light on the differences that may exist between winning and losing teams in the early and late stages of the tournament. Looking first at the prior experience variables (MMEXP), it is evident that winning teams tend to have more prior March Madness experience among their presumed starting five. In the Round of 64 and Round of 32, the winning teams averaged over 26 more minutes of previous March Madness playing time, per starter, than losing teams. From the Sweet 16 onward, the starters on winning teams boasted approximately 27 more minutes of prior March Madness experience than their losing opponents. The same trends held true with the substitutes, as winning teams' non-starters averaged 9 and 14 more minutes of prior tournament experience in the opening and closing rounds, respectively.

In terms of class rank among the starting five, it appears as though the winning teams were actually marginally younger than their opposition in both samples. Winning teams in the Round of 64 and Round of 32 also had younger substitutes, while winning teams in the later stages of the tournament actually had substitutes who were slightly older. Even so, the mean difference between winning and losing teams across all players in terms of class rank was negligible. 
Table 2

Descriptive Statistics of the Variables Grouped by Tournament Phase and Team Result

\begin{tabular}{|c|c|c|c|c|c|c|c|c|}
\hline \multirow{3}{*}{$\begin{array}{l}\text { VARIABLE } \\
\text { WIN\% }\end{array}$} & \multicolumn{4}{|c|}{ ROUNDS OF 64 \& 32} & \multicolumn{4}{|c|}{ SWEET 16 ONWARD } \\
\hline & \multicolumn{2}{|c|}{ WIN } & \multicolumn{2}{|c|}{ LOSE } & \multicolumn{2}{|c|}{ WIN } & \multicolumn{2}{|c|}{ LOSE } \\
\hline & 77.761 & $(8.880)$ & 71.429 & $(9.025)$ & 83.656 & $(7.555)$ & 79.971 & $(8.232)$ \\
\hline SOS & 11.672 & $(4.796)$ & 7.943 & $(6.277)$ & 13.427 & $(3.858)$ & 12.672 & $(4.070)$ \\
\hline ORTG & 108.569 & (4.419) & 105.838 & $(4.565)$ & 110.649 & $(4.181)$ & 109.209 & (4.134) \\
\hline$D R T G$ & 93.459 & $(4.255)$ & 95.585 & $(4.224)$ & 92.193 & $(4.171)$ & 93.348 & $(4.421)$ \\
\hline ММЕХР 5 & 64.581 & $(50.931)$ & 38.125 & $(43.225)$ & 166.557 & (72.823) & 139.456 & (61.617) \\
\hline MMEXPSUB & 21.378 & $(23.589)$ & 12.519 & $(17.402)$ & 70.867 & $(45.491)$ & 56.957 & (33.027) \\
\hline CLASS5 & 2.839 & $(0.500)$ & 2.897 & $(0.498)$ & 2.727 & $(0.585)$ & 2.821 & $(0.491)$ \\
\hline CLASSSUB & 2.290 & $(0.612)$ & 2.381 & $(0.649)$ & 2.266 & $(0.648)$ & 2.260 & $(0.603)$ \\
\hline $\mathrm{COACH}$ & 22.383 & $(24.822)$ & 12.027 & $(17.726)$ & 41.103 & $(28.928)$ & 27.697 & (24.909) \\
\hline$E H T$ & 1.522 & $(1.916)$ & 0.684 & $(2.007)$ & 2.155 & (1.867) & 1.799 & (1.855) \\
\hline MARGIN & 12.371 & (9.353) & -12.371 & (9.353) & 9.982 & (7.508) & -9.982 & (7.508) \\
\hline
\end{tabular}

Notes. The variables are represented in this table as the individual mean values for the winning and losing teams while in the models they are analyzed as the differences between the two teams in the observed game; standard deviations are in parentheses.

Though further analysis is needed, the descriptive statistics seem to suggest that class rank, alone, is not a variable that offers a discernable advantage at any stage of the tournament.

Looking lastly at the variables that were included to control for basic aspects of team quality, it is interesting to note how the gap closes between teams in terms of WIN\%, SOS, ORTG, and DRTG as the tournament progresses. This suggests the natural movement toward parity that occurs as the higher-quality teams advance and the weaker teams are eliminated. In combination with the fact that the MMEXP variables widen from the Sweet 16 onward, the initial evidence is there to support the assumption that prior experience may come into play during the later stages of the competition. The estimated models shed more light on this phenomenon, as it pertains to both a team's probability of winning (WIN) and the margin (MARGIN) by which it would be expected to do so.

\subsection{Effects on WIN}

The results of the binary probit regression $\operatorname{model}^{8}$ estimating the probability of a team winning its March Madness game are presented in Table 3. These results are presented as marginal effects in order to

Table 3

Results for Binary Probit Model with WIN as the Outcome Variable

\begin{tabular}{|c|c|c|c|c|}
\hline Variable & Estimate & S.E. & $Z$ & $P>|Z|$ \\
\hline WIN\% & 0.0073 & 0.0034 & 2.1079 & $0.0350^{* *}$ \\
\hline SOS & 0.0313 & 0.0058 & 5.4030 & $0.0000^{* * *}$ \\
\hline ORTG & 0.0127 & 0.0065 & 1.9491 & $0.0513^{*}$ \\
\hline$D R T G$ & -0.0161 & 0.0066 & -2.4536 & $0.0141^{* *}$ \\
\hline MMEXP5 & 0.0003 & 0.0006 & 0.4769 & 0.6334 \\
\hline$M M E X P S U B$ & 0.0001 & 0.0012 & 0.0817 & 0.9349 \\
\hline CLASS5 & 0.0271 & 0.0417 & 0.6517 & 0.5146 \\
\hline CLASSSUB & -0.0347 & 0.0314 & -1.1040 & 0.2696 \\
\hline $\mathrm{COACH}$ & 0.0001 & 0.0010 & 0.1014 & 0.9192 \\
\hline$E H T$ & -0.0011 & 0.0101 & -0.1052 & 0.9162 \\
\hline WIN\% * LATEROUND & 0.0033 & 0.0079 & 0.4163 & 0.6772 \\
\hline$S^{*}{ }^{*}$ LATEROUND & -0.0141 & 0.0209 & -0.6752 & 0.4995 \\
\hline ORTG $^{*}$ LATEROUND & -0.0151 & 0.0141 & -1.0763 & 0.2818 \\
\hline$D_{R T G}^{*}$ LATEROUND & 0.0236 & 0.0139 & 1.6951 & $0.0901^{*}$ \\
\hline MMEXP5 * LATEROUND & 0.0010 & 0.0009 & 1.0681 & 0.2855 \\
\hline MMEXPSUB * LATEROUND & 0.0020 & 0.0018 & 1.0888 & 0.2763 \\
\hline CLASS5 ${ }^{*}$ LATEROUND & -0.1367 & 0.0727 & -1.8803 & $0.0601^{*}$ \\
\hline CLASSSUB * LATEROUND & 0.0011 & 0.0627 & 0.0177 & 0.9859 \\
\hline COACH $^{*}$ LATEROUND & 0.0024 & 0.0016 & 1.4488 & 0.1474 \\
\hline EHT ${ }^{*}$ LATEROUND & -0.0030 & 0.0210 & -0.1403 & 0.8884 \\
\hline McFadden $\mathrm{R}^{2}$ & 0.264 & & & \\
\hline
\end{tabular}

Notes. ${ }^{* * *} p<0.01 ;{ }^{* *} p<0.05 ;{ }^{*} p<0.10$. 
show the percentage increase in a team's likelihood of winning for every one-unit increase in the explanatory variable being examined while holding all other variables constant at their means. Marginal effects offer a more interpretable value than the standard coefficients of a probit model, which are presented as $z$-scores. Looking first at the marginal effects of the explanatory variables without the late round interactions, WIN\%, SOS, ORTG, and DRTG, as the basic measures of team quality, appear to be the only variables that significantly affect a team's probability of winning in the early stages. Of these, the strength of schedule measure appears to have the largest effect, signifying the advantage enjoyed by teams that have played against high-level opposition in previous games. ${ }^{9}$

Shifting focus to the late round interaction terms, the interaction between CLASS5 and LATEROUND was negative and marginally significant $(p<0.10)$, suggesting a team would suffer a $13.67 \%$ decrease in its probability of winning in the Sweet 16 or beyond for every 1-year higher its class rank was than its opponent's. However, it is worth noting that the descriptive statistics revealed the class rank gaps between teams at these stages to be less than a full year. It would therefore be rare to encounter a team with starters who were an entire year ahead of their competitors in terms of average class rank. This makes the effect size of this variable less impactful, though the negative direction of the effect is worth highlighting. A team with starters who are of the average class rank value lower than the opposing starters will see its probability of winning increase by $1.28 \%$. Interestingly, neither of the prior March Madness experience variables (MMEXP5 and $M M E X P S U B)$ appeared to significantly contribute to a team's probability of winning in the early or late stages of the tournament.

Lastly, it merits a mention that the interaction between DRTG and LATEROUND, with a marginal effect of $2.36 \%$, appeared to show that playing stronger defense was significantly beneficial to a team's late-round success. This stands in contrast to $O R T G$, which only attained marginal significance in the overall model and did not have a significant interaction with the later rounds of the tournament.

\subsection{Effects on MARGIN}

After analyzing the effects that the explanatory variables had on a team's probability of winning, the focus was shifted to the OLS models analyzing the effects that each variable had on a team's margin of victory or defeat. The MARGIN outcome variable used in these models was particularly useful for interpreting the effects of the explanatory variables in terms of actual point values. The results are presented in Table 4. Much like the probit model, the base terms

Table 4

Results for OLS Model with MARGIN as the Outcome Variable

\begin{tabular}{|c|c|c|c|c|}
\hline Variable & Estimate & S.E. & $t$-value & $\operatorname{Pr}>|t|$ \\
\hline Constant & -0.3701 & 0.4354 & -0.8500 & 0.3957 \\
\hline WIN\% & 0.1519 & 0.0634 & 2.3980 & $0.0168^{* *}$ \\
\hline SOS & 0.9206 & 0.1020 & 9.0290 & $0.0000^{* * *}$ \\
\hline ORTG & 0.2993 & 0.1249 & 2.3950 & $0.0169^{* *}$ \\
\hline$D R T G$ & -0.3429 & 0.1246 & -2.7520 & $0.0061^{* * *}$ \\
\hline MMEXP5 & -0.0026 & 0.0106 & -0.2450 & 0.8067 \\
\hline MMEXPSUB & 0.0152 & 0.0230 & 0.6580 & 0.5106 \\
\hline CLASS5 & 0.0018 & 0.8071 & 0.0020 & 0.9982 \\
\hline CLASSSUB & -0.4117 & 0.6030 & -0.6830 & 0.4949 \\
\hline $\mathrm{COACH}$ & 0.0199 & 0.0182 & 0.6560 & 0.5119 \\
\hline$E H T$ & -0.1797 & 0.1946 & -0.9240 & 0.3560 \\
\hline WIN\% * LATEROUND & 0.0906 & 0.1556 & 0.5820 & 0.5607 \\
\hline SOS $^{*}$ LATEROUND & -0.6547 & 0.4109 & -1.5930 & 0.1116 \\
\hline ORTG $^{*}$ LATEROUND & -0.2468 & 0.2823 & -0.8740 & 0.3824 \\
\hline DRTG ${ }^{*}$ LATEROUND & 0.1828 & 0.2761 & 0.6620 & 0.5083 \\
\hline MMEXP5 * LATEROUND & 0.0389 & 0.0178 & 2.1920 & $0.0287^{* *}$ \\
\hline MMEXPSUB ${ }^{*}$ LATEROUND & -0.0052 & 0.0325 & -0.1590 & 0.8739 \\
\hline CLASS5 ${ }^{*}$ LATEROUND & -2.6517 & 1.4505 & -1.8280 & $0.0680^{*}$ \\
\hline CLASSSUB ${ }^{*}$ LATEROUND & 0.5341 & 1.2555 & 0.4250 & 0.6707 \\
\hline COACH $^{*}$ LATEROUND & 0.0245 & 0.0326 & 0.7500 & 0.4537 \\
\hline EHT ${ }^{*}$ LATEROUND & -0.2085 & 0.4237 & -0.4920 & 0.6228 \\
\hline $\mathrm{R}^{2}$ & 0.449 & & & \\
\hline
\end{tabular}


in the OLS model showed that basic measures of team quality (WIN\%, SOS, ORTG, DRTG) were the only variables to have a significant effect on the extent to which a team won or lost its March Madness game in the early stages. The strength of schedule measure was again the most impactful, indicating that nearly a 1-point advantage existed for every 1-point harder a team's schedule had been prior to the observed game. All four of the player experience variables were non-significant on their own.

However, when looking at the interaction terms, it is seen that prior March Madness experience among a team's starters (MMEXP5) is one of the few significant variables from the Sweet 16 onward. The MMEXP5 effect size of 0.039 suggests that every 1minute advantage held by a team's presumed starters in previous tournament experience leads to a 0.039 point improvement on the scoreboard. Recalling that the average experience gap between starting-fives at this stage of the tournament was nearly $27 \mathrm{~min}$ utes, this improvement swells to just over a full point when analyzed at the mean. While a 1-point improvement, on average, may not seem like much, it is worth noting that the average margin of victory/defeat in the latter stages of March Madness was just 10 points. Perhaps, then, prior experience could help teams win close games that take place late in the competition.

The interaction terms also reaffirmed what was seen in the probit model, with CLASS5 attaining a marginally significant and negative effect. Indeed, the OLS model suggests that for every 1-year higher a team is in terms of class rank, its point margin would be expected to drop by just over 2.6 points. Again considering the averages, a team with a class rank of the average value lower than its opponent would see a point boost of just 0.25 points. While the opposite effects of the MMEXP5 and CLASS5 variables may seem contradictory, the discussion section that follows sheds more light on these results.

\section{Discussion}

\subsection{Discussion of results}

This study conducted its analyses in an attempt to answer some of the questions that have been left unanswered by prior studies in the field; namely, does player experience have an effect on the performances of college basketball teams whose players may be less familiar with the high stress scenarios of the postseason than professional athletes? While the regularity with which this assumption is made in television studios and press conferences around the nation may lead one to believe that this question has long been answered, research exploring this phenomenon at the professional level has argued quite the opposite. Indeed, attempts to quantify the advantages of player experience in the NBA and NFL postseasons have found few discernible links between the amount of player experience a team has and its ability to win or perform at a higher level (Pitts, 2016; Tarlow, 2012).

Aside from the inherent limitations of the previous studies, one plausible explanation for these findings is that professional athletes have already been inoculated to stressful scenarios and have developed effective coping mechanisms for dealing with the pressure. This certainly fits with the inoculation hypothesis mentioned earlier, a theory which states that prior exposure to a stressor can increase one's ability to tolerate that stressor in the future (Eysenck, 1983). Professional athletes have been through the stress of making it to, and remaining in, the highest level of the game. They are also getting paid millions of dollars regardless of whether they win or lose. On the contrary, college athletes may be experiencing a number of stressors for the first time if they have never appeared in a major tournament. The additional media obligations and scrutiny of the national spotlight may weigh heavier on the uninitiated. As amateurs, their future income as a professional may be contingent on a successful showing in the tournament. Seeing the stark differences between collegiate and professional athletes, this study set out to examine a phenomenon that has been frequently overlooked by prior studies in the field.

While the term "experience" often carries with it a sense of ambiguity as announcers, coaches, and analysts fail to differentiate between a player's class ranking and his previous postseason experience, the empirical analyses conducted in this study defined the parameters more clearly by analyzing two forms of experience (i.e., class rank and prior March Madness experience) and their differential effects on performance in the later rounds of the tournament. One of the key findings of this study is that experience can have an impact, but perhaps not in the ways one might expect. Indeed, class rank, a variable assumed by many to be positively predictive of performance, appears to have a negative effect on both point margins and a team's probability of winning in the later stages of the tournament; that is, older teams actually 
perform significantly worse than younger teams when the pressure is highest. This stands in contrast to prior March Madness experience, which was seen in both the descriptive statistics and the OLS model to have a positive impact on team performance in the later rounds of the competition.

Clearly, though, these results cannot be considered in a vacuum, as some amount of class rank is needed in order to obtain prior experience in March Madness tournaments. A player could not simply have a greater amount of playing time in previous postseasons without having used up at least one year of eligibility. According to the descriptive statistics, the average winning team in the Sweet 16 and beyond boasted a CLASS5 value of 2.709 that would place its starters close to the junior rank. Therefore, the correct interpretation is not that class rank is unimportant, but that one of its main benefits is already being accounted for by the prior March Madness experience of its key players. Once all of the advantages of prior postseason experience are incorporated in the MMEXP measures, the class rank variables are left to essentially represent the collective "age" of a team relative to its opponent.

Taken together, these findings raise a number of interesting talking points: (1) being more experienced to the extent that a team is simply older or more mature in terms of class rank is not advantageous; rather, it is what a team has been able to do with its yearly experience (e.g., reach previous March Madness tournaments) that matters; (2) in an era full of talented, one-and-done freshmen, it might not be wholly surprising that both brands of experience have less of a positive impact than what is commonly presented; (3) keeping in line with the draft theme, one reason for why teams with a higher class rank might fare slightly worse is because their upperclassmen are not good enough to get drafted to the NBA at a younger age and may now be facingoff against teams with younger players who are more talented prospects; (4) lastly, perhaps the teams with higher class rankings fare worse because they contain a higher-than-average number of seniors who succumb to the pressures of career-ending scenarios. Moving forward, researchers could delve deeper into the impacts of one-and-done players and careerending scenarios since these are both unique facets of the college game.

It is further worth discussing how these experience variables were not significant until the later stages of the tournament when they were interacted with the LATEROUND variable. Indeed, the early round significances of the WIN\%, SOS, ORTG, and DRTG variables show that basic measures of team quality are much more vital to predicting match outcomes in the early stages of March Madness than relative measures of class rank and prior tournament experience. This makes the significance of the MMEXP5 and LATER$O U N D$ interaction in the OLS model that much more telling. After the weaker teams are eliminated in the opening two rounds and team quality becomes more even (a phenomenon that is evident in the descriptive statistics), the importance of prior experience shines through. That it is significantly and positively related to performance in what are essentially the most meaningful rounds of the tournament provides some of the clearest statistical evidence that prior experience can help college teams take command of big games where the pressure is high.

Nonetheless, while winning teams appear to have more prior March Madness experience, and advantages in the MMEXP5 category can lend additional points to a team's effort in the Sweet 16 and beyond, having an advantage in MMEXP5 does not appear to significantly improve a team's probability of winning, even in the later rounds. While the exact causes for the differences between the results of the probit and OLS results are unknown, it can be speculated that prior experience may be beneficial in terms of keeping games close or extending leads over an opponent, but that it may not consistently show up in a binary winloss column. Indeed, the average tournament game is decided by about 10 points, and the average team only improves its points margin by about one point due to previous tournament experience. So, while previous tournament experience may help a team perform better, it may not always be impactful enough to change the outcome of a game.

Furthermore, even though multicollinearity issues between the explanatory variables were taken into consideration when developing the models, it could be that prior March Madness experience, like WIN\%, $O R T G$, and $D R T G$, is serving as another proxy for talent. After all, one might expect a more experienced team to also be more adept at navigating the regular season, leading to a higher WIN\%. As such, further analysis is warranted in order to determine if prior experience is simply representative of a more abstract, higher skill-level that is endogenous to a team that consistently appears in the tournament, or if it is actually breeding intangible qualities such as composure and focus under pressure. Regardless, the significant, late-round impact of MMEXP5 on margin of victory in the face of broad-based measures 
of team quality including strength of schedule (gives precedence to advancing from a power conference), win-loss percentage, offensive rating (offensive quality), and defensive rating (defensive quality), makes a case for considering its impact as the tournament progresses. While it seems as though more tangible and traditional metrics should take precedence at the beginning of any bracket, prior March Madness experience may tip an evenly-matched Sweet 16 , Elite 8, Final Four, or National Championship game in favor of the team that possesses more.

Future studies in this realm can now focus on validating these findings, perhaps through the creation of more predictive models that incorporate prior experience variables in their forecasts. If this study provided any sort of insight in that area, it would be to suggest that variables denoting team quality should account for strength of schedule. Then, once teams become evenly matched in the later rounds of the competition, prior tournament experience should be introduced as a means of further separation. Subsequent examination is also needed in order to discover the more specific ways in which prior experience affects team performance. That is, are late-round tournament teams shooting poorly from the field or free-throw line because they have less experience handling the pressure? Are they turning the ball over more frequently because they are nervous? When questions like these are answered, coaches will be able to manage their teams more effectively.

Until then, those who are in charge of mentally and physically preparing the players for upcoming games will have to judiciously adjust their tactics and plans according to the degree of experience or inexperience that exists between a team and its opponents. Coaches or team personnel, for instance, could employ a variety of training methods and psychological techniques to ensure that inexperienced players are putting in the time to develop the proper mindset and appropriate coping mechanisms. Halliwell (2004), for example, highlighted the benefits of interactionist techniques that can help place athletes in the proper mood and mindset ahead of a big event. In particular, it was noted how veteran players should be instructed to "let their training and talent come out," while the more inexperienced players should be given access to the "timeless wisdom" of the veterans through special meetings, video clips, and inspirational quotes (p. 30). Ultimately, while some amount of psychological training could prove helpful, the more data-driven, focused interventions could eventually yield more powerful results.

\subsection{Current limitations and recommendations for future research}

One of the clear limitations of this study is that it is only focused on one specific postseason within one specific sport. While March Madness holds a prominent place in the wider realm of collegiate sport, one cannot generalize these findings to football, women's basketball, or other team-based competitions until further analyses are conducted. Looking ahead to subsequent studies in this area, it would be interesting to see if some of the more discrete variables underlying overall performance are affected by experience. This might help quantify some of the more intangible qualities of a team (e.g., confidence, composure, and hustle). For instance, do teams with more prior experience shoot better from the foul line or make a higher percentage of their shots from the field? Do the teams with more upperclassmen turn the ball over less frequently or fight harder for rebounds? This could be viewed at the team level or by comparing relative experience across positions that match up with one another. For example, experience levels could be averaged according to each position, much like height was for centers and power forwards in Pomeroy's (2008) effective height measure. The relative levels of experience among players at these positions could then be compared across the statistical categories that are commonly associated with them. Power forwards and centers, for example, could be compared in terms of rebounding while guards could be compared in relation to how they shoot and handle the ball.

In addition, one of the limitations of this study was that it did not incorporate any specific time or game-scenario variables. It is therefore suggested that future studies collect and incorporate some of these measures in order to provide more powerful and interpretable estimates of performance under pressure. For example, one study by Goldman and Rao (2012) on NBA players performing under pressure assigned a value of importance to each free-throw based on the time remaining in the game and the score differential between the two teams. A similar method could be adopted to include experience variables in an effort to see whether or not a player's level of experience helped him or her perform better or worse at shooting under pressure. Another recommendation involves the use of more longitudinal, team-specific models. Instead of observing individual, head-to-head matchups, future analyses could employ methods such as multinomial logistic regression to examine the impact that the explanatory variables have on the 
number of March Madness games that a team can be expected to win. Methods and variables that better account for the potential latent talent issues that exist between the control variables for team quality and player experience could also be introduced in an effort to shed further light on the significant or nonsignificant impacts of experience on performance. Lastly, future researchers could develop variables that account for postseason experience in college basketball tournaments outside of March Madness, such as the National Invitation Tournament (NIT) or College Basketball Invitational (CBI).

\section{Conclusion}

In closing, this study showed that the experience assumption so frequently espoused by media members and other March Madness affiliates is largely overstated. Simply being a more veteran team with a higher class rank does not appear to offer any significant advantages outside of being a vehicle for prior March Madness experience, which did display a significant and positive (albeit small) effect on margins of victory in the later rounds of the tournament. Therefore, under the right conditions, prior experience may be beneficial to high-level athletic performers in the college setting, a finding that differs marginally from previous studies that have attempted to invalidate the experience assumption at the professional level. From a theoretical perspective, the findings align with the assumptions of the inoculation hypothesis, whereby previous exposure to a stressor can reduce anxiety in future encounters with that stressor. The results also hold practical implications for team personnel and bracketologists who may wish to implement measures and models that account for intangible attributes like experience. Nonetheless, it is important to remember that these findings were taken from one specific sport within one specific context. Future studies will need to validate and test this proposition across a wider variety of sports and settings.

\section{Notes}

1. It is up to the discretion of the conferences to determine how the units earned by their participating teams are allocated. While the NCAA encourages conferences to share this money equally, each conference is allowed to distribute the money as it sees fit. Some conferences do not fully disclose how they distribute basketball fund revenues to their member teams.

2. The study by Tarlow (2012) did find that NBA player experience positively predicted the number of regular season games a team won. The author concluded that experience may help a team make the playoffs, but that it does not help a team win once it is in the playoffs. In addition, the study found that coach experience did increase a team's ability to win in the playoffs.

3. Despite Pitts' (2016) assertions that experience did not matter in the NFL postseason, a categorical variable signifying whether or not a team was starting a new quarterback in the playoffs was shown to significantly decrease a team's chances of winning. This shows that extreme cases of inexperience at a key position may be detrimental to team performance.

4. If the individual teams are treated as the observations in a binary probit regression model, then the outcomes for two teams competing in the same game are errantly considered to be independent events such that $\mathrm{P}$ (team $i$ wins) $\neq 1$ - $\mathrm{P}$ (team $j$ wins). Therefore, the game should be treated as the observation in order to produce mutually exclusive probabilities such that $\mathrm{P}$ (team $i$ wins $)=1-\mathrm{P}$ (team $j$ wins).

5. For a more detailed explanation of the strength of schedule ratings, visit https://www. team rankings.com/blog/site-updates/siteupdate-new-rankings-beta-college-footballpolls-page.

6. Margin of victory variables were initially included but had to be removed for multicollinearity reasons.

7. Second-order, quadratic terms for the MMEXP and $C L A S S$ variables were investigated but were not found to be significant. They offered no improvement to either type of model.

8. Logistic regression methods were also performed and yielded nearly identical results.

9. Models were constructed with interaction terms between SOS and WIN\%, ORTG, and DRTG, but none of these interaction terms were significant.

\section{Acknowledgments}

The authors would like to extend a special thank you to David Schmidt and Britton Gallardo for their efforts in helping collect the data that were 
used in this study. In addition, they would also like to acknowledge the helpful feedback provided by the anonymous reviewers for the Journal of Sports Analytics.

\section{References}

Anderson, K., 2016, In March Madness, Anything Can Happen. Sportsblog.com. http://kennyanderson.sportsblog.com/posts/ 14575807/in-march-madness-anything-can-happen.html [Accessed 1 May 2017].

Anshel, M.H., Robertson, M. and Caputi, P., 1997, Sources of Acute Stress and Their Appraisals and Reappraisals among Australian Police as a Function of Previous Experience, Journal of Occupational and Organizational Psychology, 70(4), 337-356.

Baumann, R., Matheson, V.A. and Howe, C., 2010, Anomalies in Tournament Design: The Madness of March Madness, Journal of Quantitative Analysis in Sports, 6(2), 1-9.

Baumeister, R.F., 1984, Choking Under Pressure: SelfConsciousness and Paradoxical Effects of Incentives on Skillful Performance, Journal of Personality and Social Psychology, 46(3), 610.

Baumeister, R.F. and Showers, C.J., 1986, A Review of Paradoxical Performance Effects: Choking Under Pressure in Sports and Mental Tests, European Journal of Social Psychology, 16(4), 361-383.

Beilock, S.L. and Carr, T.H., 2001, On the Fragility of Skilled Performance: What Governs Choking Under Pressure? Journal of Experimental Psychology: General, 130(4), 701.

Boulier, B.L. and Stekler, H.O., 1999, Are Sports Seedings Good Predictors?: An Evaluation, International Journal of Forecasting, 15(1), 83-91.

Carlin, B.P., 1996, Improved NCAA Basketball Tournament Modeling Via Point Spread and Team Strength Information, The American Statistician, 50(1), 39-43.

Caudill, S.B., 2003, Predicting Discrete Outcomes with the Maximum Score Estimator: The Case of the NCAA Men's Basketball Tournament, International Journal of Forecasting, 19(2), 313-317.

Doty, S., 2017, March Madness Betting To Top \$10 Billion, American Gaming Association. https://www.americangaming. org/newsroom/press-releasess/march-madness-betting-top10-billion [Accessed 1 May 2017].

Eysenck, H.J., 1983, Stress, Disease, and Personality: The Inoculation Effect. In Stress Research: Issues for the Eighties, edited by C. L. Cooper, 121-146. Chichester, England: Wiley.

Goff, B., 2000, Effects of University Athletics on the University: A Review and Extension of Empirical Assessment, Journal of Sport Management, 14(2), 85-104.

Goldman, M. and Rao, J.M., 2012, Effort vs. Concentration: The Asymmetric Impact of Pressure on NBA Performance. Paper presented at the MIT Sloan Sports Analytics Conference, Boston, MA.

Halliwell, W., 2004, Preparing Professional Hockey Players for Playoff Performance Athletic Insight: The Online Journal of Sport Psychology, 6(2), 25-33.
Harville, D.A., 2003, The Selection or Seeding of College Basketball or Football Teams for Postseason Competition, Journal of the American Statistical Association, 98(461), 17-27.

Hoegh, A., Carzolio, M., Crandell, I., Hu, X., Roberts, L., Song, Y. and Leman, S.C., 2015, Nearest-Neighbor Matchup Effects: Accounting for Team Matchups for Predicting March Madness, Journal of Quantitative Analysis in Sports, 11(1), 29-37.

Humphreys, B.R. and Mondello, M., 2007, Intercollegiate Athletic Success and Donations at NCAA Division I Institutions, Journal of Sport Management, 21(2), 265.

Ingold, D. and Pearce, A., 2015, March Madness Makers and Takers. Bloomberg. http://www.bloomberg.com/graphics/2015march-madness-basketball-fund/ [Accessed 1 May 2017].

Jacobson, S.H. and King, D.M., 2009, Seeding in the NCAA Men's Basketball Tournament: When is a Higher Seed Better? Journal of Gambling Business and Economics, 3(2), 63.

Jacobson, S.H., Nikolaev, A.G., King, D.M. and Lee, A.J., 2011, Seed Distributions for the NCAA Men's Basketball Tournament, Omega, 39(6), 719-724.

Khatibi, A., King, D.M. and Jacobson, S.H., 2015, Modeling the Winning Seed Distribution of the NCAA Division I Men's Basketball Tournament, Omega, 50, 141-148.

Kubatko, J., Oliver, D., Pelton, K. and Rosenbaum, D.T., 2007, A Starting Point for Analyzing Basketball Statistics, Journal of Quantitative Analysis in Sports, 3(3), 1-22.

Kvam, P. and Sokol, J.S., 2006, A Logistic Regression/Markov Chain Model for NCAA Basketball, Naval Research Logistics (NrL), 53(8), 788-803.

Larsson, G., Kempe, C. and Starrin, B., 1988, Appraisal and Coping Processes in Acute Time-Limited Stressful Situations: A Study of Police Officers, European Journal of Personality, 2(4), 259-276.

Lopresti, M., 2016, March Madness: Last Chance for Nation's Top Seniors to Make NCAA Tournament Run, NCAA. http://www.ncaa.com/news/basketball-men/article/2016-0314/march-madness-last-chance-nations-top-seniors-makencaa [Accessed 1 May 2017].

Moskowitz, T. and Wertheim, L.J., 2011, Scorecasting: The Hidden Influences behind How Sports are Played and Games are Won. New York: Random House.

Moyer, C., 2016, March Madness Brackets Boost Tournament Viewership by $21 \%$. American Gaming Association. https:// www.americangaming.org/newsroom/press-releasess/ march-madness-brackets-boost-tournament-viewership-21 [Accessed 1 May 2017].

Norris, F.H. and Murrell, S.A., 1988, Prior Experience as a Moderator of Disaster Impact on Anxiety Symptoms in Older Adults, American Journal of Community Psychology, 16(5), 665-683.

Osburn, S., Smeltz, N. and Sabatelle, J., 2016, Turner, CBS and the NCAA Reach Long-Term Multimedia Rights Extension for NCAA Division I Men's Basketball Championship. NCAA. https://www.ncaa.org/about/resources/media-center/news/ turner-cbs-and-ncaa-reach-long-term-multimedia-rightsextension-ncaa-division-i-men-s-basketball?sf24203015=1 [Accessed 1 May 2017].

Pallotta, F., 2015, March Madness is a TV Slam Dunk: Highest Ratings in 22 Years. CNN. http://money.cnn.com/ 2015/04/07/media/march-madness-tv-ratings/ [Accessed 1 May 2017]. 
Pedderson, J.K. and Madden, C., 2016, Employers Brace for March Madness, Challenger, Gray, and Christmas, Inc. https://www.challengergray.com/press/press-releases/ employers-brace-march-madness [Accessed 1 May 2017].

Pitts, J.D., 2016, Determinants of Success in the National Football League's Postseason: How Important is Previous Playoff Experience? Journal of Sports Economics, 17(1), 86-111.

Pomeroy, K., 2008, The Height of Expectations: Measuring Vertical Impact, Basketball Prospectus. http://www. basketballprospectus.com/article.php?articleid $=82$ [Accessed 1 May 2017].

Quińones, M.A., Ford, J.K. and Teachout, M.S., 1995, The Relationship between Work Experience and Job Performance: A Conceptual and Meta-Analytic Review, Personnel Psychology, 48(4), 887-910.

Robst, J., VanGilder, J., Berri, D.J. and Vance, C., 2011, “Defense Wins Championships": The Answer from the Gridiron. International Journal of Sport Finance, 6(1), 72-84.

Rovell, D., 2016, ACC Stands to Make More than \$30 Million from NCAA Tournament Run. ESPN. http://espn.go.com/menscollege-basketball/story/」id/15029265/acc-stands-makemore-30-million-ncaa-tournament-success [Accessed 1 May 2017].

Schwertman, N.C., Schenk, K.L. and Holbrook, B.C., 1996, More Probability Models for the NCAA Regional Basketball Tournaments, The American Statistician, 50(1), 34-38.
Smith, C., 2017, How the ACC Can Make $\$ 38$ million from the NCAA Tournament, Forbes. https://www.forbes. com/sites/chrissmith/2017/03/16/how-the-acc-can-make38-million-from-the-ncaa-tournament/\#44de0858331e [Accessed 1 May 2017].

Smith, T. and Schwertman, N.C., 1999, Can the NCAA Basketball Tournament Seeding be Used to Predict Margin of Victory? The American Statistician, 53(2), 94-98.

Tarlow, J., 2012, Experience and Winning in the National Basketball Association. Paper presented at the MIT Sloan Sports Analytics Conference, Boston, MA.

Van Kemenade, J.F., Van Son, M.J. and Van Heesch, N.C. 1995, Performance Anxiety among Professional Musicians in Symphonic Orchestras: A Self-Report Study. Psychological Reports, 77(2), 555-562.

Wallace, H.M., Baumeister, R.F. and Vohs, K.D., 2005, Audience Support and Choking Under Pressure: A Home Disadvantage? Journal of Sports Sciences, 23(4), 429-438.

Wolstat, R., 2014, Mercer Relies on Experience in Huge Upset of Duke, Toronto Sun. http://www.torontosun.com/ 2014/03/21/mercer-relies-on-experience-in-huge-upset-ofduke [Accessed 1 May 2017]. 